\title{
Impact of sample size on variation of adverse events and preventable adverse events: systematic review on epidemiology and contributing factors
}

\author{
Constanze Lessing, ${ }^{1}$ Astrid Schmitz, ${ }^{1}$ Bernhard Albers, ${ }^{2}$ Matthias Schrappe ${ }^{1}$
}

- Additional appendix are published online only. To view these files please visit the journal online (http://qshc.bmj. com).

${ }^{1}$ Institute for Patient Safety, University of Bonn, Bonn, Germany

${ }^{2}$ German Diabetes Center at the Heinrich-Heine University, Düsseldorf, Germany

\section{Correspondence to}

Dr Constanze Lessing, Institute for Patient Safety, University of Bonn, D-53111 Bonn, Germany; lessing@ukb.uni-bonn.de

Accepted 2 November 2009 Published Online First 2 August 2010

\section{UNLOCKID}

This paper is freely available online under the BMJ Journals unlocked scheme, see http:// qshc.bmj.com/site/about/ unlocked.xhtml

\begin{abstract}
Objectives To perform a systematic review of the frequency of (preventable) adverse events (AE/PAE) and to analyse contributing factors, such as sample size, settings, type of events, terminology, methods of collecting data and characteristics of study populations. Review methods Search of Medline and Embase from 1995 to 2007. Included were original papers with data on the frequency of $A E$ or PAE, explicit definition of study population and information about methods of assessment. Results were included with percentages of patients having one or more AE/PAE. Extracted data enclosed contributing factors. Data were abstracted and analysed by two researchers independently.
\end{abstract}

Results 156 studies in 152 publications met our inclusion criteria. 144/156 studies reported AE, 55 PAE (43 both). Sample sizes ranged from 60 to 8493876 patients (median: 1361 patients). The reported results for AE varied from $0.1 \%$ to $65.4 \%$, and for PAE from $0.1 \%$ to $33.9 \%$. Variation clearly decreased with increasing sample size. Estimates did not differ according to setting, type of event or terminology. In studies with fewer than 1000 patients, chart review prevailed, whereas surveys with more than 100000 patients were based mainly on administrative data. No effect of patient characteristics was found.

Conclusions The funnel-shaped distribution of $A E$ and PAE rates with sample size is a probable consequence of variation and can be taken as an indirect indicator of study validity. A contributing factor may be the method of data assessment. Further research is needed to explain the results when analysing data by types of event or terminology.

\section{INTRODUCTION}

Following the Institute of Medicine (IOM) report 'To Err is Human' in 1999, there has been much debate on the true incidence of adverse events (AE), and preventable adverse events (PAE). ${ }^{1}$ Several studies at national level and with the Harvard Medical Practice Design (see below) have found results for $\mathrm{AE}$ up to $16.6 \%$, and for PAE up to $8.4 \%{ }^{2-12}$ of inpatients. Variations in the figures were soon considered, and several systematic reviews have covered this issue. ${ }^{13}$

Systematic reviews are restricted by the diversity of studies. One strategy to deal with it is to refine research so as to focus on particular healthcare settings or subgroups of endpoints such as medication-related events ${ }^{14-18}$ or events leading to hospital admission. ${ }^{19-24}$ Only loose attempts have been made in mapping $\mathrm{AE}$ across the total healthcare system comprehensively, however. ${ }^{25-27}$
The present systematic review aims to specify the overall incidence of $\mathrm{AE}$ and PAE across all settings and procedures, so as to describe the influence of heterogeneity factors such as sample size, settings, type of events, terminology, methods of collecting data or characteristics of the study population. We hypothesise that variation of incidence is explained primarily by sample size.

\section{METHODS}

\section{Search strategy}

The present article is part of a broader literature research on the epidemiology of patient safety, ${ }^{28}$ and looks at papers giving frequencies of $\mathrm{AE}$ and PAE as percentages of patients affected. We began with a search in Medline and Embase for studies published between January 1995 and October 2007. Key words (truncated) were: 'AE*,' 'PAE*,' 'negligent $\mathrm{AE}^{*}$,' 'adverse medical device event*', 'medication error*,' 'medical error*,' 'near miss*,' 'adverse drug event*' and 'iatrogenic illness*.' This search was limited to titles and abstracts. References cited in the studies retrieved were examined in order to identify additional publications.

Articles in English, German, Spanish, French, Portuguese, Danish and Norwegian were considered. Other languages were approved when there was an English abstract containing data essential for extraction. Articles identified were reviewed at full-text level.

\section{Selection}

To be included, studies had to meet the following five criteria: (1) original paper; (2) a specified study population; (3) data collected on AE or PAE or both; (4) explicit information given about the study method; and (5) results reported as percentages of patients affected. AE was defined as any patientrelated injury caused by clinical management rather than by the underlying disease, and PAE was defined as an $\mathrm{AE}$ resulting from error, and therefore avoidable. ${ }^{12} 29$ Patient populations might represent all patients in an institution, patients related to a defined medical specialty, or patients in an entire sector of care such as drug therapy or nosocomial infections.

A study was considered as an article on a single study population. Papers reporting results from different study populations were regarded as two or more studies. In the case of duplicate publications, only the primary or the one reporting overall results was included. Intervention studies were included with baseline data before the implementation of risk prevention. When several assessment methods 
were used, we extracted combined results as far as possible. Studies limited to single diseases or isolated procedures were excluded.

\section{Data abstraction}

Retrieved studies were assessed independently by two reviewers and controlled twice. Discrepancies were resolved by discussion. Data on the frequency of AE and PAE were extracted. Additional variables were the number of patients included, information on healthcare settings, classification according to types of event and terminology, method of collecting data and patient characteristics. We distinguished between medication-related, procedurerelated and all types of events. We also distinguished between AE terminologies used by different authors. Two main groups were discerned. The first group refers to the definition of the IOM, 'an AE is an injury resulting from a medical intervention, or in other words, it is not due to the underlying disease'. 'The second group apply to the definition due to the WHO of adverse drug events/adverse drug reactions as 'any response to a drug which is noxious, unintended and which occurs at doses normally used in man for the prophylaxis, diagnosis or therapy of disease'. ${ }^{30}$ All other definitions were summarised in a third definition group. Among methods of collecting data, we distinguished between chart review, computer-based alerts, direct observation, voluntary reporting, critical incident reporting systems, interviews, clinical surveillance and the analysis of administrative data, usually in the form of codes from the International Statistical Classification of Diseases and Related Health Problems (ICD). ${ }^{31}$ We chose to distinguish between three types of chart review: prospective, retrospective and the Harvard Medical Design. The latter was developed especially to detect $\mathrm{AE}$ and PAE, and consists of a retrospective structured two-staged review process. ${ }^{32} 33$

\section{Quantitative data synthesis}

Abstracted data were entered into a Microsoft Access database for further analysis (Microsoft, Seattle, Washington). Frequencies of outcome measures were recorded or calculated as numbers and percentages of patients. Data were rounded to one decimal place. Patient subgroups were totalled, if we were sure that every patient was included only once.

\section{RESULTS}

\section{Trial flow}

Our primary research found a total of 241 studies in 230 publications that matched our inclusion criteria. A total of 156 studies gave results as percentages of patients affected by $\mathrm{AE}$ or PAE, see figure 1 (full list of references in Appendix 1, available online only).

\section{Study characteristics}

In total, the 156 studies in our review reported results on 23696252 patients. Sample size varied from 60 patients ${ }^{34}$ to 8493876 patients. ${ }^{35}$ The median sample size was 1361 patients, the 25 th percentile was 379 patients, and the 75 th percentile was 14766 patients.

AE as a single outcome measure was observed in 101/156 $(64.7 \%)$ of studies, $12(7.8 \%)$ observed PAE, and $43(27.6 \%)$ observed both. Studies were performed in 27 countries, primarily in highly developed industrial countries, headed by the USA (51 surveys). Most studies were short-term; $55.1 \%$ lasted more than 6 months, but only $25.6 \%$ lasted more than 1 year. Patients were treated in distinct healthcare settings. One hundred and one

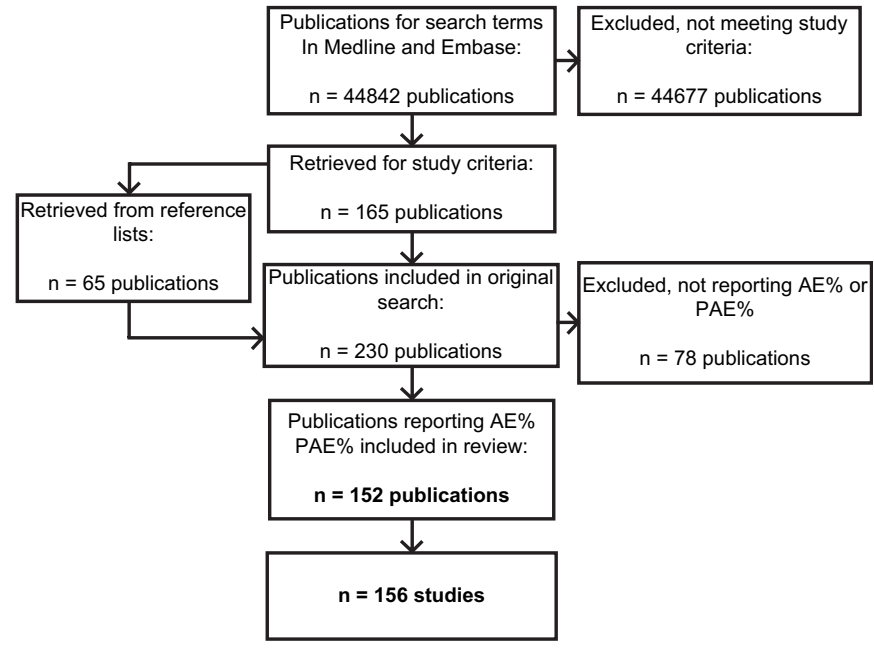

Figure 1 Flow chart of studies retrieved and included in the systematic review. $\mathrm{AE}$, adverse event; $\mathrm{PAE}$, preventable adverse event.

studies examined inhospital patients, nine surveys looked at ambulatory care, 39 looked at ambulant patients leading to hospital admission, three studies took place in long-term care, and four studies were conducted in other settings. When samples consisted of hospital patients, tertiary hospitals and academic centres prevailed. Most studies were limited to single institutions (101/156 cases). In general, all medical disciplines were concerned (17 medical specialties were distinguished), but when a specific choice was made, this depended principally on the organisational structure of the wards and hospital. Ninetyseven of 156 surveys concentrated on a single discipline. Thirtynine of these were concerned with internal medicine, 16 with paediatrics and nine with surgery. We also found that 50/156 studies reported on all types of events, 99/156 were medicationrelated, and 7/156 were procedure-related.

Studies used different methods for collecting data. Ninetyseven surveys were restricted to a single collection method, and 59 papers used a combination of two or more methods. As a single measuring instrument, a chart review prevailed in 43/97 studies, followed by clinical surveillance (13/97) and ICD codes (11/97). Among combinations, the use of chart review with interviews was most common (19/59). A summary of all studies included is given in Appendix 2, available online only.

\section{Incidence of AE and PAE by sample size}

Frequencies of $\mathrm{AE}$ ranged from $0.1 \%$ to $65.4 \%$. Most studies $(129 / 156)$ reported results between $0.1 \%$ and $30 \%$ (median $8.9 \%$, IOR 12.9). Incidences of PAE ranged from $0.1 \%$ to $33.9 \%$. Almost all studies $(53 / 55)$ reported results between $0.1 \%$ and $20 \%$ (median 4.8\%, IOR 5.4).

To provide a more detailed picture of the distribution of results, we plotted the results against study size. Figure 2 shows the distribution of $\mathrm{AE}$ estimates in correlation to the size of the study population.

We observe a broad variation in smaller studies having fewer than 1000 patients. In studies with more than 1000 patients, the spread decreases rapidly, and even falls below 20\% in studies with more than about 2000 patients. With only one exception, the results of surveys with approximately 15000 patients or more do not exceed $10 \%{ }^{36}$

For PAE, the plot looks similar, although extreme outliers are missing within small studies (figure 3); however, the fraction of 


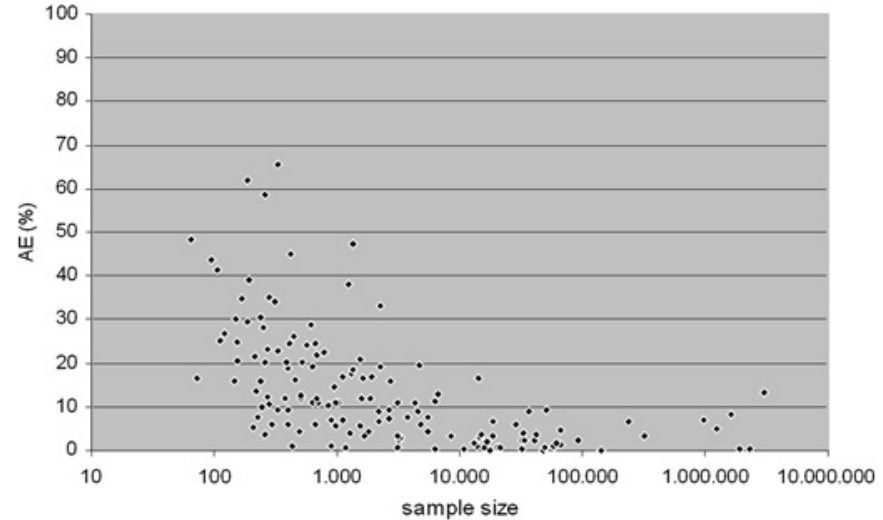

Figure 2 Adverse event estimates in correlation to sample size ( $n=144$ studies), sample size displayed with half logarithmic-scale.

small studies is smaller for PAE than for AE, and the same is true for very large studies.

Nonetheless, percentages clearly decrease with sample size. In studies with approximately 2000 patients, the results fall below $10 \%$, and below the $1 \%$ mark in studies with more than 20000 patients. All scatter plots exhibit a visible correlation between the frequency of $\mathrm{AE}$ and PAE and sample size.

\section{Effect of setting, types of events, terminology and methods of collecting data}

We next analysed whether variation is due to further factors. We found that results do not differ between healthcare settings, countries or medical specialties. More surprisingly, we did not even find any clear disparities between different types of events, although the frequency of AE related to medications or procedures is expected to be lower than the overall results. Figure 4 shows the distribution for adverse drug events, procedure-related events and all types of AE (figure 4).

The data for terminology show a similar distribution. There is no difference in variation between studies using the terminology of the IOM, the WHO or others (figure 5, a list of all definitions of $\mathrm{AE}$ used is given in Appendix 3, available online only).

In relation to data-collecting methods, there is no difference in estimates between studies that use a single method to detect events, and surveys that operate with two or more methods. In contrast assessment techniques differ according to sample size, especially for AE (figure 6).

Interviews as a single method are restricted to small studies with some hundred patients included,,$^{37-42}$ whereas compila-

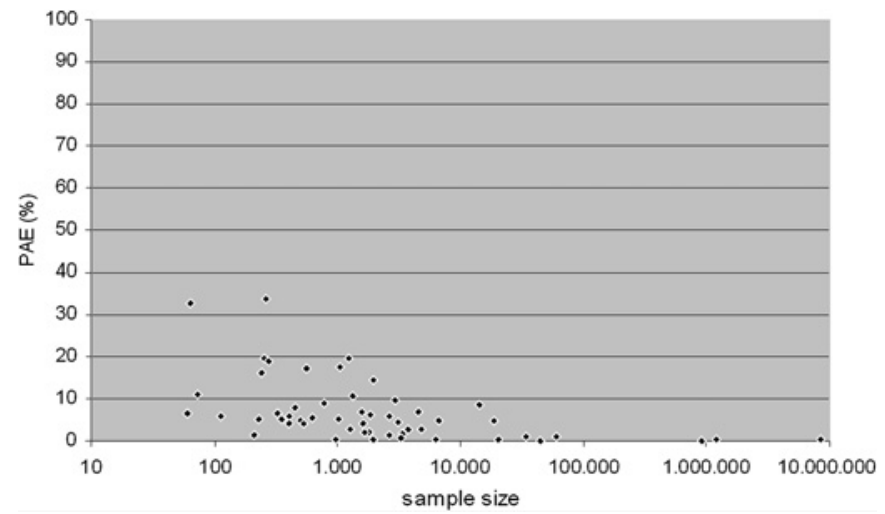

Figure 3 Preventable adverse event estimates in correlation to sample size $(n=55$ studies), sample size displayed with half logarithmic-scale.

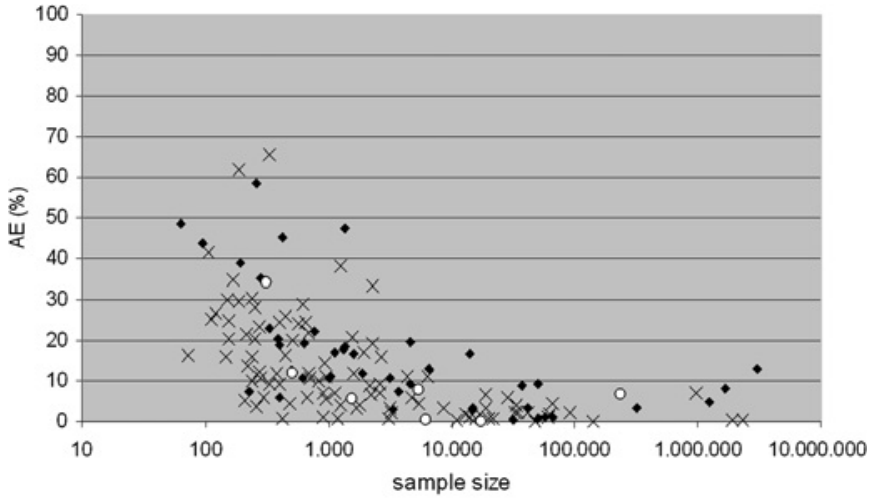

- all types of events Xadverse drug events oprocedure related events

Figure 4 Adverse event estimates by event type ( $n=144$ studies).

tions of ICD codes are used in large trials involving up to millions of patients. ${ }^{43-51}$ Six of nine surveys with more than 100000 patients are based on ICD codes, and the frequencies of $\mathrm{AE}$ in these studies range from $0.1 \%$ to $8.3 \%$. All studies with results exceeding $30 \%$ and one single method to detect $\mathrm{AE}$ rely on prospective or retrospective chart review. Also, 8/9 surveys with combined methods use prospective chart review, mainly in combination with interviews (3/8). The distribution is less clear for PAE.

\section{Characteristics of study populations}

Information on the effect of patient characteristics was inconsistent. The distribution of gender is displayed in 46/156 surveys; 58/156 studies give the mean ages. Only 54/156 studies report health status, referring mainly to the Charlson Index (11/ 54). ${ }^{52}$ Eighty-one of 156 surveys report on patient deaths. None of these data suffice to give information about possible dependence of variation on study population characteristics.

\section{DISCUSSION}

In our systematic review, we included 156 studies on the frequency of $\mathrm{AE}$ and PAE. Studies were of great heterogeneity, and estimates varied widely from $0.1 \%$ to $65.4 \%$ for $\mathrm{AE}$, and from $0.1 \%$ to $33.9 \%$ for PAE. Previous reviews found less variation. Von Laue et al compiled estimates for AE ranging between $2.9 \%$ and $16.6 \%$, Aranaz et al from $3.7 \%$ to $16.6 \%$, and de Vries et al from $4.6 \%$ to $12.4 \%$. Discrepancies are largely because search strategies were more contracted, and the number of studies included was smaller.

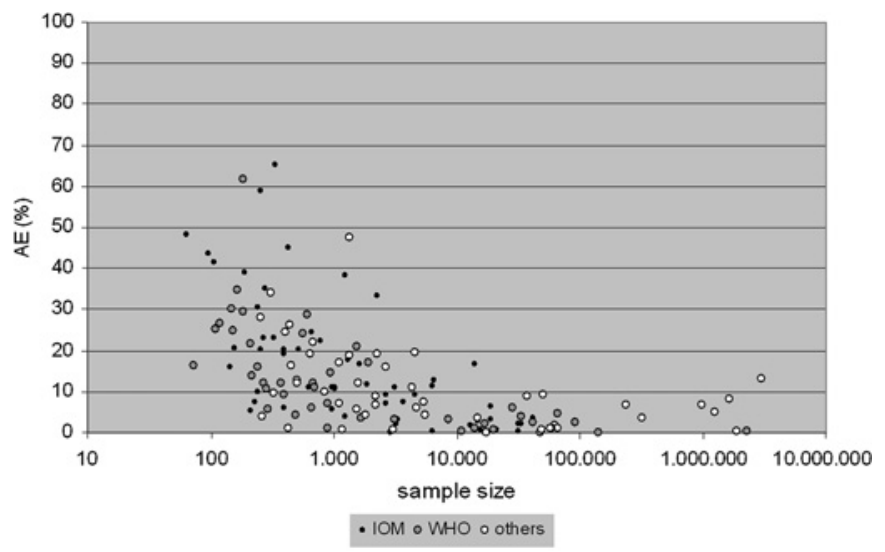

Figure 5 Adverse event estimates by AE terminology ( $n=144$ studies). 


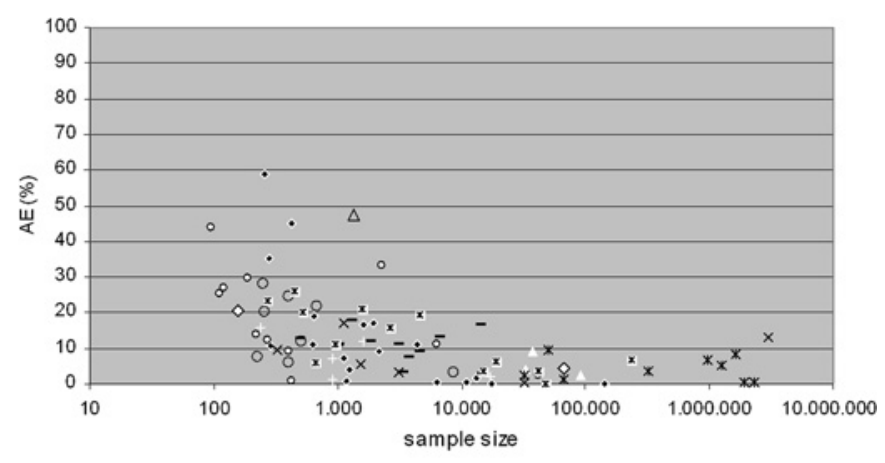

\begin{tabular}{|c|c|c|}
\hline - retrospective chart review & o prospective chart review & computer based allerts \\
\hline$\Delta$ direct observation & + voluntary reporting & o critical incident reporting systems \\
\hline o interview & $\times$ routine data & - Harvard Medical Practice Design \\
\hline$x$ others & $\mathbf{x}$ clinical surveilance & \\
\hline
\end{tabular}

Figure 6 Adverse event estimates by types of data collection methods, only single methods are displayed ( $n=88$ studies).

Our aim was to display the overall body of published evidence in order to shed light on the diversity of studies and results. To consider study size as an approximation for strength of evidence, we plotted outcomes against the size of the study population and observed that variation decreased with the number of patients included. As one would expect results to spread in small studies as a simple rule of statistics, we interpret the distribution of results as an indirect indicator for validity. This pattern was much clearer for AE than for PAE, due primarily we believe to the smaller number of studies on PAE. This consequence of missing data has been described in the context of metaanalyses. ${ }^{53}$

We found no other factors to explain this pattern of variation. Neither different settings nor event types had any effect, that is, we found no differences between frequencies reported by surveys on the total of events and surveys examining medication-related or procedure-related $\mathrm{AE}$ only. The same is true for terminology; diverse definitions of $\mathrm{AE}$ make no difference to frequencies. One reason might be indifference to precise definition of terms. For example, few papers using the WHO terminology differentiate between adverse drug reactions and adverse drug events, terms sometimes used to distinguish between preventable and non-preventable patient injuries. These findings suggest that research methods should be refined, and results may not always display the true dimension of $\mathrm{AE}$ and PAE.

Very large surveys show a clear tendency for results to be less than $1 \%$. This could be due to the relation between sample size and assessment methods. Whereas large surveys with more than 100000 patients are almost exclusively restricted to ICD-coded events, many small trials prefer chart review, or combinations with chart review. ICD coding is able to display only a fraction of events, which might explain the comparatively low estimates. ${ }^{54-56}$ Conversely, this does not follow for small studies with chart review. The assumption that high frequencies may correlate with small studies because they look at cases more carefully is opposed by the observation that results are not restricted to remarkably high results but show a distribution which is primarily due to statistical dispersion, and only additionally fortified by the choice of methods to collect data.

Another observation is that papers with above-average results indicate that the majority involved high-risk patients and very old or very young patients. Eight of 16 publications with results on $\mathrm{AE}$ above $30 \%$ dealt with elderly patients, ${ }^{57-64}$ and two observed children. ${ }^{65}{ }^{66}$ Unfortunately, data were not sufficient for further analysis.
We conclude that the precision of $\mathrm{AE}$ and $\mathrm{PAE}$ estimates depends primarily on sample size and to some degree on methods to collect data. This second observation remains difficult for interpretation. In our judgement as a consequence the informative value of very small surveys should be considered with scepticism, as well as that of very large ones. Since $54.9 \%$ of studies on AE (84/153) and $60.3 \%$ of studies on PAE (35/58) deal with study populations either smaller than 1000 patients or larger than 50000 patients the generalisibility of these papers must be reassessed.

We believe the present review to be the largest systematic review of the incidence of $\mathrm{AE}$ and PAE ${ }^{18}{ }^{24}$ Only one previous review detected a correlation between incidence and sample size but did not give any explanation. ${ }^{24}$ Others suggested explanations but did not verify these. ${ }^{2022} 24$

The present review has limitations. It is part of a wider research effort and is limited to surveys of the percentages of $\mathrm{AE} / \mathrm{PAE}$. Consequently, estimates of errors or near misses were not considered. Another limiting factor is that PAE has not yet been investigated to the same extent as AE. Also, we searched only the Medline and Embase databases. Due to our broad research strategy, results exhibit a high heterogeneity, so there was no indication to summarise results in a meta-analysis.

Our findings affirm that $\mathrm{AE}$ and PAE are serious problems across all healthcare settings and medical procedures, but some questions remain about the consistency of methods of collecting and reporting data. Further research should concentrate on advancing methods especially for small settings and specific types of event.

Acknowledgements The authors thank all student assistants for the time and care they spent in assisting data management: H Doll, F Schwartz, J Streck, P Ottlitz, H Cramer, H Brehmer, D Meyer, J Bellach, M Schmedemann, A Bailey, C Kloss and J Schott.

Funding The project 'patient safety: investigation of the international status quo, assignment on the German healthcare system, and need for action' was funded by the German ministry of health.

\section{Competing interests None}

Provenance and peer review Not commissioned; externally peer reviewed.

\section{REFERENCES}

1. Kohn LT, Corrigan JM, Donaldson MS. To err is human: building a safer health system. Committee on Quality of Health Care in America, ed. Washington, D.C: National Academy Press, 1999:1-223.

2. Brennan TA, Leape LL, Laird NM, et al. Incidence of adverse events and negligence in hospitalized patients. Results of the Harvard Medical Practice Study I. N Engl J Med 1991;324:370-6.

3. Leape LL, Brennan TA, Laird N, et al. The nature of adverse events in hospitalized patients. Results of the Harvard Medical Practice Study II. N Engl J Med 1991;324:377-84.

4. Wilson RM, Runciman WB, Gibberd RW, et al. The Quality in Australian Health Care Study. Med J Aust 1995;163:458-71.

5. Thomas EJ, Studdert DM, Burstin HR, et al. Incidence and types of adverse events and negligent care in Utah and Colorado. Med Care 2000;38:261-71.

6. Schiøler T, Lipczak H, Pedersen BL, et al. Incidence of adverse events in hospitals. A retrospective study of medical records. Ugeskr Laeger 2001;163:5370-8.

7. Vincent C, Neale G, Woloshynowych M. Adverse events in British hospitals: preliminary retrospective record review. BMJ 2001;322:517-19.

8. Davis $\mathbf{P}$, Lay-Yee R, Briant $\mathrm{R}$, et al. Adverse events in New Zealand public hospitals I: occurrence and impact. N Z Med J 2002;115:U271.

9. Davis $\mathbf{P}$, Lay-Yee R, Briant $R$, et al. Adverse events in New Zealand public hospitals II: preventability and clinical context. N Z Med J 2003;116:U624.

10. Baker GR, Norton PG, Flintoft V, et al. The Canadian Adverse Events Study: the incidence of adverse events among hospital patients in Canada. CMAJ 2004;170:1678-86.

11. Aranaz JM, Limón R, Requena J, et al. Incidencia e impacto de los efectos adversos en dos hospitales. Revista Calidad Asistencial 2005;20:53-60.

12. Michel $\mathbf{P}$, Quenon JL, de Sarasqueta AM, et al. Comparison of three methods for estimating rates of adverse events and rates of preventable adverse events in acute care hospitals. BMJ 2004;328:199. 
13. Stelfox HT, Palmisani S, Scurlock C, et al. The 'To Err is Human' report and the patient safety literature. Qual Saf Health Care 2006;15:174-8.

14. Elder NC, Dovey SM. Classification of medical errors and preventable adverse events in primary care: a synthesis of the literature. J Fam Pract 2002;51:927-32.

15. Kanjanarat $\mathbf{P}$, Winterstein AG, Johns TE, et al. Nature of preventable adverse drug events in hospitals: a literature review. Am J Health Syst Pharm 2003;60:1750-9.

16. von Laue NC, Schwappach DL, Koeck CM. The epidemiology of preventable adverse drug events: a review of the literature. Wien Klin Wochenschr 2003;115:407-15.

17. Puche CE, Luna JD. Adverse drug reactions: an update review of the problem in Spain. Rev Clin Esp 2006;206:336-9.

18. Krahenbuhl-Melcher A, Schlienger R, Lampert M, et al. Drug-related problems in hospitals: a review of the recent literature. Drug Saf 2007;30:379-407.

19. Einarson TR. Drug-related hospital admissions. Ann Pharmacother 1993;27:832-40.

20. Muehlberger N, Schneeweiss S, Hasford J. Adverse drug reaction monitoring - cost and benefit considerations. Part I: frequency of adverse drug reactions causing hospital admissions. Pharmacoepidemiol Drug Saf 1997:(Suppl 6)3:S71-S77.

21. Roughead EE, Gilbert AL, Primrose JG, et al. Drug-related hospital admissions: a review of Australian studies published 1988-1996. Med J Aust 1998;168:405-8.

22. Winterstein AG, Sauer BC, Hepler CD, et al. Preventable drug-related hospital admissions. Ann Pharmacother 2002;36:1238-48.

23. Alonso HP, Otero López MJ, Maderuelo Fernández JA. Ingresos hospitalarios causados por medicamentos: incidencia, características y coste. Farmacia Hospitalaria 2002;26:77-89.

24. Beijer HJ, de Blaey CJ. Hospitalisations caused by adverse drug reactions (ADR): a meta-analysis of observational studies. Pharm World Sci 2002;24:46-54.

25. von Laue NC, Schwappach DL, Koeck CM. The epidemiology of medical errors: a review of the literature. Wien Klin Wochenschr 2003:115:318-25.

26. Aranaz JM, Aibar C, Gea MT, et al. Adverse effects in hospital healthcare. A critical review. Med Clin (Barc) 2004;123:21-5.

27. de Vries EN, Ramrattan MA, Smorenburg SM et al. The incidence and nature of inhospital adverse events: a systematic review. Qual Saf Health Care 2008;17:216-23.

28. As part of the Research Project 'Patient safety: investigation of the international status quo, assignment on the German healthcare system and determination of need for action' our research group conducted the described literature search. The research project was funded by the German ministry of health. First results are published (in German). http://www.aktionsbuendnis-patientensicherheit.de.

29. Barach P, Moss F. Delivering safe health care. BMJ 2001;323:585-6.

30. World Health Organization (WHO), International Drug Monitoring. The Role of the Hospital (WHO Technical Report Series No. 425) Geneva 1969.

31. International Classification of Diseases. http://www.who.int/classifications/icd/en/.

32. Hiatt HH, Barnes BA, Brennan TA, et al. A study of medical injury and medical malpractice. NEJM 1989;321:480-4

33. Brennan TA, Localio AR, Leape LL, et al. Identification of adverse events occurring during hospitalization. A cross-sectional study of litigation, quality assurance, and medical records at two teaching hospitals. Ann Intern Med 1990;112:221-6.

34. Vira T, Colquhoun M, Etchells E. Reconcilable differences: correcting medication errors at hospital admission and discharge. Qual Saf Health Care 2006;15:122-6.

35. Bond CA, Raehl CL, Franke T. Medication errors in United States hospitals. Pharmacotherapy 2001;21:1023-36.

36. Madigan EA. A description of adverse events in home healthcare. Home Health Nurse 2007;25:191-7.

37. Gray SL, Mahoney JE, Blough DK. Adverse drug events in elderly patients receiving home health services following hospital discharge. Ann Pharmacother 1999:33:1147-53.

38. Forster AJ, Rose NG, van WC, et al. Adverse events following an emergency department visit. Qual Saf Health Care 2007;16:17-22.

39. Rask KJ, Wells KJ, Teitel GS, et al. Can an algorithm for appropriate prescribing predict adverse drug events? Am J Manag Care 2005;11:145-51.

40. Tafreshi MJ, Melby MJ, Kaback KR, et al. Medication-related visits to the emergency department: a prospective study. Ann Pharmacother 1999;33:1252-7.
41. Chrischilles E, Rubenstein L, Van GR, et al. Risk factors for adverse drug events in older adults with mobility limitations in the community setting. J Am Geriatr Soc 2007:55:29-34.

42. Weingart SN, Pagovich 0, Sands DZ, et al. What can hospitalized patients tell us about adverse events? Learning from patient-reported incidents. J Gen Intern Med 2005:20:830-6.

43. Carroll R, McLean J, Walsh M. Reporting hospital adverse events using the Alfred Hospital's morbidity data. Aust Health Rev 2003;26:100-5.

44. Ehsani JP, Jackson T, Duckett SJ. The incidence and cost of adverse events in Victorian hospitals 2003-04. Med J Aust 2006;184:551-5.

45. Kanter DE, Turenne W, Slonim AD. Hospital-reported medical errors in premature neonates. Pediatr Crit Care Med 2004:5:119-23.

46. Corral BS, Guerrero A, Beltran GM, et al. Use of MBDS as a tool for the detection of drug-related adverse events. Farmacia Hospitalaria 2004;28:258-65.

47. Meurer JR, Yang H, Guse CE, et al. Medical injuries among hospitalized children Qual Saf Health Care 2006;15:202-7.

48. O'Hara DA, Carson NJ. Reporting of adverse events in hospitals in Victoria, 1994-1995. Med J Aust 1997:166:460-3.

49. Rozenfeld S. Drug adverse events in hospitals in the State of Rio de Janeiro, Brazil. Rev Saude Publica 2007:41:108-15.

50. Jackson T, Duckett S, Shepheard J, et al. Measurement of adverse events using 'incidence flagged' diagnosis codes. J Health Serv Res Policy 2006;11:21-6.

51. Chyka PA. How many deaths occur annually from adverse drug reactions in the United States? Am J Med 2000;109:122-30.

52. Charlson ME, Pompei P, Ales KL. A new method of classifying prognostic comorbidity in longitudinal studies: development and validation. J Chronic Dis 1987:40:373-83.

53. Egger M, Davey SG, Schneider M, et al. Bias in meta-analysis detected by a simple graphical test. BMJ 1997;315:629-34.

54. Iezzoni LI. Using administrative diagnostic data to assess the quality of hospital care. Pitfalls and potential of ICD-9-CM. Int J Technol Assess Health Care 1990;6:272-81.

55. Smith GS, Langlois JA, Buechner JS. Methodological issues in using hospital discharge data to determine the incidence of hospitalized injuries. Am J Epidemiol 1991;134:1146-58

56. Romano PS, Chan BK, Schembri ME, et al. Can administrative data be used to compare postoperative complication rates across hospitals? Med Care 2002; 40:856-67

57. Cooper JW. Probable adverse drug reactions in a rural geriatric nursing home population: a four-year study. J Am Geriatr Soc 1996;44:194-7.

58. Passarelli MC, Jacob-Filho W, Figueras A. Adverse drug reactions in an elderly hospitalised population: inappropriate prescription is a leading cause. Drugs Aging 2005;22:767-77

59. Carvalho-Filho ET, Saporetti L, Souza MA, et al. latrogeny in hospitalized elderly patients. Rev Saude Publica 1998:32:36-42.

60. Mannesse CK, Derkx FH, de Ridder MA, et al. Adverse drug reactions in elderly patients as contributing factor for hospital admission: cross sectional study. BMJ 1997; 315:1057-8

61. Gurwitz JH, Field TS, Judge J, et al. The incidence of adverse drug events in two large academic long-term care facilities. Am J Med 2005:118:251-8.

62. Kessomboon P, Panarunothai S, Wongkanaratanakul P. Detecting adverse events in Thai hospitals using medical record reviews: agreement among reviewers. J Med Assoc Thai 2005;88:1412-18.

63. Hanlon JT, Schmader KE, Koronkowski MJ, et al. Adverse drug events in high risk older outpatients. J Am Geriatr Soc 1997;45:945-8.

64. Chan M, Nicklason F, Vial JH. Adverse drug events as a cause of hospital admission in the elderly. Intern Med J 2001;31:199-205

65. Larsen GY, Donaldson AE, Parker HB, et al. Preventable harm occurring to critically ill children. Pediatric Critical Care Medicine 2007:8:331-6.

66. Proctor ML, Pastore J, Gerstle JT, et al. Incidence of medical error and adverse outcomes on a pediatric general surgery service. J Pediatr Surg 2003;38:1361-5. 